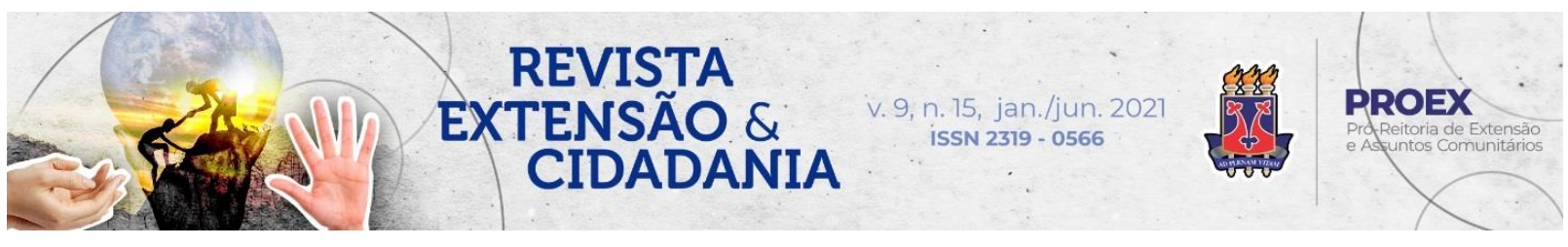

DOI: $10.22481 /$ recuesb.v9i15.8630

\title{
PROJETO CENTRO DE REFERÊNCIA PARALÍMPICO DE RORAIMA: CONTRIBUIÇÕES PARA A INICIAÇÃO PARALÍMPICA
}

\section{Paralympic Reference Center in Roraima: contributions to paralympic initiation}

\author{
José Paulo da Silva Rocha ${ }^{1}$ \\ Lucas Portilho Nicoletti ${ }^{2}$ \\ Silvestre Cirilo dos Santos Neto ${ }^{3}$ \\ Vinícius Denardin Cardoso ${ }^{4}$
}

\begin{abstract}
Resumo: Os Centros de Referência Paralímpico foram criados com objetivo de descobrir novos talentos e renovar as gerações de atletas com deficiência para que possam consolidar o Brasil a permanecer entre as principais potências do esporte paralímpico mundial. O objetivo desse estudo é descrever a importância da implementação do Centro de Referência Paralímpico no estado de Roraima. Trata-se de um estudo de caso descritivo com abordagem qualitativa. Participaram do estudo dois professores do Centro de Referência Paralímpico de Roraima. As entrevistas foram conduzidas através do aplicativo de Google Meet (em decorrência da Pandemia do COVID-19 e o distanciamento social). Os resultados demonstram que a possibilidade de fomentar e ampliar a iniciação esportiva pelo Centro de Referência é a principal categoria destacada pelos professores, seguido da transformação social que o Centro de Referência pode trazer para a vida do atleta com deficiência e, ainda, a oportunidade de desenvolvimento do esporte paralímpico no estado. Dessa forma, destacamos a relevante contribuição do Centro de Referência Paralímpico às pessoas com deficiência e para o desenvolvimento do esporte paralímpico em Roraima.
\end{abstract}

Palavras-chave: Iniciação Esportiva. Esporte Paralímpico. Desenvolvimento Esportivo.

\footnotetext{
${ }^{1}$ Graduado em Educação Física, pela Universidade Estadual de Roraima - UERR, Boa Vista, RR, Brasil. Orcid: 0000-0003-2146-2506 E-mail: josepaulosilvarocha1010@gmail.com

${ }^{2}$ Doutor em Educação, pela Unicamp. Professor efetivo da Universidade Estadual de Roraima - UERR, Boa Vista, RR, Brasil. Orcid: 0000-0003-1069-2728 E-mail: lucas.nicoletti@uerr.edu.br

${ }^{3}$ Doutor em Ciências do Exercício e do Esporte, pela UERJ. Pesquisador do Centro de Estudos Olímpicos, Rio de Janeiro, RJ, Brasil. Orcid: 0000-0001-8628-9308 E-mail: silvestrecirilo@yahoo.com.br

${ }^{4}$ Doutor em Ciências do Movimento Humano, pela UFRGS. Professor efetivo da Universidade Estadual de Roraima - UERR, Boa Vista, RR, Brasil. Orcid: 0000-0003-4669-4290 E-mail: vinicius.denardin@uerr.edu.br
} 


\begin{abstract}
The Paralympic Reference Centers were created with the objective of discovering new talents and renewing the generations of athletes with disabilities so that they can consolidate Brazil to remain among the main powers of the Paralympic sport worldwide. The purpose of this study is to describe the importance of implementing the Paralympic Reference Center in the state of Roraima. This is a descriptive case study with a qualitative approach. Two teachers from the Paralympic Reference Center of Roraima participated in the study. The interviews were conducted through the Google Meet application (due to the COVID-19 Pandemic and social distance). The results demonstrate that the possibility of promoting and expanding sports initiation by the Reference Center is the main category highlighted by the teachers, followed by the social transformation that the Reference Center can bring to the life of the athlete with a disability, and also, the opportunity of development of Paralympic sports in the state. In this way, we highlight the relevant contribution of the Paralympic Reference Center to people with disabilities and for the development of Paralympic sport in Roraima.
\end{abstract}

keywords: Sports Initiation. Paralympic Sport. Paralympic Development.

\title{
Introdução
}

A história do Movimento Paralímpico como conhecemos hoje começa remotamente com a Segunda Guerra Mundial (1939-1945), quando os feridos de guerra foram enviados ao Hospital Stoke Mandeville. O Dr. Ludwig Guttman reconheceu o valor fisiológico e psicológico dos esportes na reabilitação desses pacientes (LEGG; STEADWARD, 2011; BRITTAIN, 2012). Dessa forma, a reabilitação funcionou como fator de integração social, principalmente quando se percebeu que o esporte proporcionava bons resultados no tratamento médico. Esse protocolo adotado pelo Dr. Guttman levou, em 1948, à realização dos Jogos Stoke Mandeville, considerados a origem do Movimento Paralímpico como o conhecemos hoje. Essa integração entre a medicina e o esporte tem impacto direto nos esportes para pessoas com deficiência.

Em 1951, com a disseminação desse protocolo de reabilitação médica em hospitais britânicos, pacientes de outros países passaram a participar desses Jogos, dando início ao seu processo de internacionalização, que culminou com a realização dos Primeiros Jogos Paralímpicos, em Roma, em 1960 (BRITTAIN, 2010; LEGG; STEADWARD, 2011). Como Guttman realizou os primeiros Jogos Stoke Mandeville no mesmo dia da abertura dos Jogos Olímpicos de 1948, em Londres, a proposta foi realizar os Jogos Paralímpicos na mesma cidade-sede dos Jogos Olímpicos. Nas edições 1960 e 1964, Guttman atingiu esse objetivo, mas por causa do tratamento de segunda classe dado a este evento, os Jogos Olímpicos e Paralímpicos só foram sediados na mesma cidade em 1988 (BRITTAIN, 2010; 2012).

Revista Extensão \& Cidadania, v. 9, n. 15, p. 64-73, jan./jun. 2021. 
Assim, o esporte para pessoas com deficiência (PCD) surgiu como um importante meio na reabilitação física, psicológica e social desse segmento populacional, consiste em adaptações e modificações em regras, materiais e locais para o desenvolvimento das atividades para proporcionar a participação das PCD nas diversas modalidades esportivas (GORGATTI; COSTA, 2013).

Cardoso (2011) afirma que o esporte para PCD ganhou relevância em nosso país e no mundo, novos adeptos, novas competições, novas modalidades, novas metodologias e um grande interesse científico contribuem a cada dia para o aprimoramento do esporte para pessoas com deficiência. O Esporte Paralímpico Brasileiro cresce a cada nova competição internacional, os resultados das últimas competições deixam isso em evidência. Primeiro colocado em quatro edições de Jogos Parapanamericanos seguidas (2007, 2011, 2015 e 2019) e a permanência no Top 10 dos últimos três Jogos Paralímpicos (2008, 2012 e 2016) demonstram que o país é uma das atuais potências paralímpicas.

Mais difícil que chegar a esses resultados expressivos é se manter entre as principais potências. Dessa forma, podemos inferir que o desempenho é um continuum desde o planejamento até o resultado alcançado por um atleta ou equipe. De acordo com O'Boyle e Hassan (2014, p. 301), a gestão de desempenho pode ser conceituada como "uma abordagem holística para o desempenho que abrange várias dimensões de desempenho que podem ser fundamentais para o cumprimento eficaz da missão de uma organização", na mesma direção, Bosscher et al. (2008) afirmam que o planejamento estratégico é um processo que poderá proporcionar o desenvolvimento de atletas de elite de sucesso.

Percebeu-se o crescimento de clubes e atletas das mais diversas modalidades paralímpicas e em diferentes regiões do país. Porém, as estruturas esportivas ainda deixavam a desejar quando se pensava em iniciação e treinamentos especializados em esportes paralímpicos. Assim, a implementação de infraestrutura, capacitação de profissionais e fomento à pesquisa científica na área do esporte paralímpico servem como uma alternativa para ampliar e aprimorar o desenvolvimento da iniciação esportiva no esporte paralímpico em todas as regiões do país.

Pensando nisso, em 2019, o Comitê Paralímpico Brasileiro (CPB) criou os Centros de Referência Paralímpico com a meta de descobrir novos talentos e renovar as gerações de atletas com deficiência para que possam consolidar o Brasil a permanecer entre as principais potências do esporte paralímpico mundial (PEREIRA et al., 2019). Ainda de acordo com Pereira et al. (2019), o projeto Centro de Referência tem entre seus objetivos: treinar e oferecer o suporte

Revista Extensão \& Cidadania, v. 9, n. 15, p. 64-73, jan./jun. 2021. 
necessário aos atletas da iniciação até ao alto rendimento; capacitar professores de Educação Física para atuar no esporte paralímpico e ainda, promover projetos de pesquisa com a temática do esporte paralímpico, favorecendo o acesso de pessoas com deficiência ao esporte.

Até o final de 2019, o CPB implementou 13 Centros de Referência no Brasil (RR, AM, GO, DF, SP-Itu, PR, ES, SE, SC-Blumenau, MG Belo Horizonte e Uberlândia e ainda RJ CEFAN e CEMS), e a meta estipulada até os Jogos Paralímpicos de Los Angeles, Estados Unidos, em 2024, é termos um Centro de Referência Paralímpico em cada uma das 27 Unidades Federativas do Brasil.

Em Roraima, a implantação do Centro de Referência ocorreu através de uma parceria entre a Universidade Estadual de Roraima (UERR) e o Comitê Paralímpico Brasileiro (CPB). Inicialmente cadastrado como um Projeto de Extensão da Universidade, as atividades foram sendo aprimoradas e ampliadas e hoje fazem parte de um Termo de Cooperação Técnica entre as referidas Instituições.

Dessa forma, este estudo tem o objetivo de descrever a importância da implementação do Centro de Referência Paralímpico no estado de Roraima pela visão dos professores de Educação Física.

\section{Procedimento metodológico}

Participaram do estudo dois professores do Centro de Referência Paralímpico de Roraima, são profissionais com 7,4 anos de experiências na Educação Física, sendo 2,3 anos de atuação direta no esporte paralímpico. O estudo foi aprovado pelo Comitê de Ética em Pesquisa com Seres Humanos da Universidade Estadual de Roraima (CEP/UERR), sob o número: 32225720.9.0000.5621, Parecer n. 4.147.686.

O presente trabalho foi realizado através de um estudo de caso que, de acordo com Yin (2010, p.41), dentre as aplicações para o estudo de caso está a “de descrever uma intervenção e o contexto da vida real que ela aconteceu". A abordagem escolhida para a condução do estudo foi a qualitativa. As entrevistas foram conduzidas através do aplicativo Google Meet (em decorrência da Pandemia do COVID-19 e o distanciamento social), em horário definido, em acordo com os entrevistados. Somente após o consentimento para participação e gravação foi iniciada a entrevista.

Revista Extensão \& Cidadania, v. 9, n. 15, p. 64-73, jan./jun. 2021. 
Para coleta de informações utilizou-se a entrevista semiestruturada, que possibilitou os sujeitos discorrerem livremente sobre o tema proposto (QUEIRÓS; LACERDA, 2013). Assim o roteiro de entrevista ficou assim estabelecido:

1. Qual a relevância de se ter um CENTRO DE REFERÊNCIA PARALÍMPICO no seu estado?

2. Na sua opinião, qual a importância de se ter um CENTRO DE REFERÊNCIA PARALÍMPICO em todas as Unidades Federativas do Brasil?

3. Quais as contribuições que o CENTRO DE REFERÊNCIA PARALÍMPICO pode trazer para o desenvolvimento do Esporte Paralímpico do seu estado? E do país?

Para a análise das informações foi utilizado Análise de Conteúdo (BARDIN, 2010). A análise de conteúdo é definida por Bardin (2010, p. 44) como:

\footnotetext{
Um conjunto de técnicas de análise das comunicações visando-se obter, por procedimentos sistemáticos e objetivos de descrição de conteúdo das mensagens (quantitativos ou não) que permitam a inferência de conhecimentos relativos às condições de produção/recepção (variáveis inferidas) destas mensagens.
}

De uma forma mais simples, a análise de conteúdo é vista por Vergara (2008, p.15) como "uma técnica para o tratamento de dados que visa identificar o que está sendo dito a respeito de um tema".

Para a definição das unidades de análise adotadas, que também é conhecida como unidade de registro, e é definida por Bardin (2010) como a unidade a ser codificada. Com estas variáveis levantadas, realizou-se a categorização que, segundo Bardin (2010, p.145), é "uma operação de classificação de elementos constitutivos de um conjunto por diferenciação, e posteriormente, por reagrupamento segundo gênero (analogia) com os critérios previamente definidos". Essa categorização utilizou o sistema aberto, pois "as categorias são definidas durante o andamento da pesquisa" (VERGARA, 2008, p.18).

\section{Resultados e discussões}

Após a análise das informações, chegou-se a três categorias, conforme discurso dos professores entrevistados: Iniciação Esportiva, Transformação Social e Oportunidade de

Revista Extensão \& Cidadania, v. 9, n. 15, p. 64-73, jan./jun. 2021. 
Desenvolvimento do Esporte. A seguir, discutimos cada uma das categorias elencadas nos discursos.

A possibilidade de fomentar e ampliar a Iniciação Esportiva pelo Centro de Referência é a principal categoria elencada pelos professores, conforme podemos perceber nos discursos seguintes:

P1: “[...] desenvolvimento das suas coordenações motoras, desenvolvimento do seu psicológico (...) vai trazer essa nova forma de vida a essas pessoas e essas nova forma de vida nada mais é que uma forma atlética $[. .$.$] "$

P2: “[...] é a oportunidade que o CPB tá tendo de implantar os centros de referência paralímpico possibilita e... descoberta de novos atletas facilita a iniciação da base de treinamento na localidade [...]"

Ao abordar a Iniciação Esportiva, Fernandes (2019) entende que é um processo que se inicia assim que as crianças têm suas primeiras vivências com os jogos até o final dos 14 anos de idade, tendo o seu desenvolvimento de habilidades e capacidades ocorrendo de forma diversificada, motivante, respeitando a especificidade de cada modalidade praticada, servindo de bases para as futuras especializações nas modalidades escolhidas pelos próprios praticantes.

A iniciação tem por objetivo o que seu próprio nome já diz, iniciar um indivíduo a uma prática esportiva, dando a ele acesso a novas possibilidades de práticas, despertando novos motivos até que chegue a se tornar uma atividade regular, possibilitando que o indivíduo seja um praticante ativo.

Para ilustrar como seria em relação ao esporte paralímpico, podemos utilizar o exemplo da bocha paralímpica que, de acordo com Piculli (2016), a super proteção dos pais deve ser quebrada, pois eles acreditam não ser possível uma criança com deficiência severa, praticar esportes ou fazer atividades físicas.

Ainda conforme Piculli (2016), as dificuldades chegam ao sistema de ensino, que não desenvolve a educação física adaptada. Nesse sentido, é o professor que está no chão da quadra. Este, muitas vezes, não teve uma formação adequada ou não tem o espaço adequado para desenvolver um trabalho de inclusão. A junção do espaço com a formação adequada permitiria a desenvoltura de atividades em grupo, cujas habilidades fundamentais são praticadas e a alfabetização motora é adquirida dentro das suas capacidades.

Por outro lado, Cardoso (2016) destaca que o atleta paralímpico deve superar algumas barreiras inicialmente que podem dificultar o seu desenvolvimento dentre elas estão a falta de

Revista Extensão \& Cidadania, v. 9, n. 15, p. 64-73, jan./jun. 2021. 
recursos; falta de profissionais especializados e a ausência de uma estrutura de treinamento de qualidade.

Nessa perspectiva, a implantação de Centros de Referência Paralímpico em cada Unidade Federativa do Brasil pode favorecer o aprimoramento da iniciação esportiva e o desenvolvimento de atletas paralímpicos no país.

Em relação ao Centro de Referência Paralímpico do Estado de Roraima, observamos a facilidade do acesso que o atleta tem com o centro de treinamento, diminuindo o desgaste financeiro em relação à locomoção, facilitando a iniciação esportiva e uma possível descoberta de um novo talento nacional para o esporte paralímpico.

Desta forma, Centro de Referência Paralímpico surge como uma possibilidade com foco em otimizar o desempenho dos atletas, a fim da conquista de melhores resultados em competições, como também inovar na metodologia de treinamentos e aprendizagem e garantir a manutenção da saúde e melhoria da qualidade de vida das PCD.

Também é perceptível para os professores a Transformação Social que o Centro de Referência pode trazer para a vida do atleta com deficiência.

P1: “[...] ferramenta de transformação, de educação e uma ferramenta essencial "pra' uma sociedade, "pra" um grupo, "pra" uma certa quantidade de pessoas que vê no esporte, que busca no esporte, uma auto superação."

P2: “[..] 'pra' que eles conheçam as modalidades paralímpicas que serão desenvolvidas num local que seja visto o desenvolvimento [...] esportivo e não um local de reabilitação que [...] as pessoas com deficiências tenham a possibilidade de competições [...]."

A prática de atividades esportivas para PCD além de proporcionar todos os benefícios para seu bem estar e qualidade de vida, também é a oportunidade de testar seus limites e potencialidades, prevenir as enfermidades secundárias à sua deficiência e promover a integração social e a reabilitação da pessoa com deficiência (CARDOSO, 2011).

Sassaki (2002) e Marques (2016) relatam que a inclusão das PCD é caracterizada por um processo contínuo, que necessita de transformações nas estruturas sociais em diferentes setores e instâncias. Dependem de configurações que sejam favoráveis no ambiente e os agentes e ainda, ações individuais dessa própria população.

Marques (2016) afirma que a inclusão social é um processo meticuloso e que se liga à quebra de paradigmas, estereótipos e preconceitos. De tal forma o autor acredita que a educação

Revista Extensão \& Cidadania, v. 9, n. 15, p. 64-73, jan./jun. 2021. 
formal, a mídia e fenômenos socioculturais são capazes de causar e incentivar a inclusão social das PCD rompendo todas as formas de preconceito.

Desse modo, Cardoso (2011) afirma que o esporte adaptado é uma ferramenta de importante na reabilitação de indivíduos com deficiência, pelos benefícios motores, psicológicos e sociais, além de terem como objetivos o lazer e a competição, que são considerados aceleradores do processo de reabilitação.

Portanto, a transformação na vida das PCD é perceptível, cada objetivo alcançado na prática esportiva, amplia a motivação para permanecer engajado, acarretando benefícios motores, psicológicos e sociais, que podem ampliar a qualidade de vida.

Também percebemos que o Desenvolvimento Esportivo é relatado pelos professores:

P1: “[...] elas podem sim realizar prática esportiva, elas podem sim ser um ídolo, ser um herói e ser exemplos e espelhos 'pra' uma multidão, pra uma sociedade inteira que traz os esportistas olímpicos ou paralímpicos como heróis, como alguém que se superou um dia."

P2: "[...] isso contribui muito "pro" desenvolvimento do esporte paralímpico como um todo, além de intercâmbio entre os Estados nas proximidades, por exemplo entre Roraima e Amazonas que não era uma realidade."

O desenvolvimento do paradesporto vem desde a época das Grandes Guerras, período em que era quase impossível pensar em reabilitação, uma vez que muitos soldados retornavam mutilados, com perda de audição e distúrbios motores. Observando o cenário, o médico alemão Ludwig Gutmann introduziu o esporte enquanto método de reabilitação dos seus pacientes, obtendo resultados superiores quando comparados com os métodos de reabilitação em vigor até então.

Cardoso et al. (2019) destacam que a oportunidade da prática esportiva se tornou de grande eficácia para o desenvolvimento de um estilo de vida saudável para pessoas com deficiência, é também uma oportunidade de testar suas potencialidades, encorajando e possibilitando seu ingresso em práticas esportivas de alto rendimento.

É nessa vertente que entra o Centros de Referência Paralímpico, pois surge a possibilidade do desenvolvimento de novos atletas, o que é um dos objetivos do centro de referência, a manutenção de novos atletas desde a iniciação até o alto rendimento de acordo com Pereira et al. (2019).

Nesse ritmo, com a implantação dos Centros de Referência em todas as unidades federativas, vão ao encontro à evolução da geração de atletas paralímpicos brasileiros o que

Revista Extensão \& Cidadania, v. 9, n. 15, p. 64-73, jan./jun. 2021. 
possibilita a descoberta de talentos que podem vir a ser os novos espelhos para a próxima geração paralímpica brasileira.

\section{Considerações finais}

O esporte para pessoas com deficiência está em evidência no país e no mundo, novas competições, novas modalidades e o interesse científico contribuíram para o seu elevado crescimento. É perceptível a importância do país ter vários centros espalhados pelo seu território, não somente pela possibilidade de descoberta de novos talentos, mas pela oportunidade de levar às PCD um sentimento de esperança, uma vontade de se superar a cada dia provando o seu valor a quem não acreditava que poderia ser possível que o indivíduo com deficiência pudesse praticar esporte e ser vitorioso.

Notamos que a transformação acontece, seja ela psicológica, motora ou social. É fato que o esporte muda vidas, altera as perspectivas de futuro, o esporte paralímpico/adaptado deve ser tratado não somente como lazer ou competição, mas como um facilitador no processo de reabilitação. A implementação de Projetos de Extensão em Universidades são fundamentais para proporcionar o desenvolvimento de atividades físicas e esportivas para pessoas com deficiência, e podem ser aliados para o aprimoramento dessas atividades, podendo favorecer também, o desenvolvimento de talentos esportivos paralímpicos.

\section{Referências}

BARDIN, L. Análise de conteúdo. 5. ed. Lisboa: Edições 70, 2010.

BOSSCHER, V. et al. The global sporting arms race: an international comparative study on sports policy factors. In: BOSSCHER, V. et al. Leading to International Sporting Success. Oxford: Meyer \& Meyer Sport, 2008.

BRITTAIN, I. From Stoke Mandeville to Stratford: a history of the summer Paralympic Games. Common Ground, Champaign, IL, 2012.

BRITTAIN, I. Disability sport is going back to its roots: rehabilitation of military victims of violent conflict in the twenty-first century. Leisure Studies Association Conference. Leeds Metropolitan University, UK, 6, 8 July, 2010.

CARDOSO, V. D. A reabilitação de pessoas com deficiência através do desporto adaptado. Revista Brasileira de Ciências do Esporte, v. 33, n. 2, p. 529-539, 2011.

Revista Extensão \& Cidadania, v. 9, n. 15, p. 64-73, jan./jun. 2021. 
CARDOSO, V. D. et al. Motivos para a continuidade de atletas no esporte paralímpico brasileiro. Revista iberoamericana de psicología del ejercicio y el deporte, v. 14, n. 1, p. 8$11,2019$.

CARDOSO, V. D. O desenvolvimento da carreira esportiva de atletas paraolímpicos no Brasil. Tese (Doutorado em Ciências do Movimento Humano) - Escola de Educação Física, Fisioterapia e Dança, Programa de Pós-Graduação em Ciências do Movimento Humano, Universidade Federal do Rio Grande do Sul, Porto Alegre, 2016.

FERNANDES, F. C. O esporte para pessoas com deficiência física: da iniciação esportiva à prática regular. Dissertação (Mestrado em Educação Física) - Faculdade de Educação Física, Universidade Estadual de Campinas, Campinas, 2019.

GORGATTI, M. G.; COSTA, R. F. de Vida Atividade Física Adaptada - Qualidade Para Pessoas Com Necessidades Especiais. São Paulo: Manole, 2013.

LEGG, D.; STEADWARD, R. The Paralympic Games and 60 years of change (1948-2008): unification and restructuring from a disability and medical model to sport-based competition. Sport in Society, v.14, n. 9, p. 1099-1115, 2011.

MARQUES, R. F. R. A contribuição dos Jogos Paralímpicos para a promoção da inclusão social o discurso midiático como um obstáculo. Revista USP, São Paulo, v.108, p. 87-96, 2016.

O'BOYLE, I.; HASSAN, D. Performance management and measurement in national-level non-profit sport organizations. European Sport Management Quarterly, v.14, n. 3, p. 299$314,2014$.

PEREIRA, R.; CABRAL, S. I. C.; BARBOZA, F.; PEREIRA, E. M. L.; SOUZA, S.; PEREIRA, L. Coordenação de esporte escolar do Comitê̂ Paralímpico Brasileiro: projetos de massificação do esporte paralímpico nacional. In: OLIVEIRA, A. F. S.; HAIACHI, M. C. (org.). V Ciclo de Debates em Estudos Olímpicos e Paraolímpicos: o futuro dos jogos olímpicos e paraolímpicos. Florianópolis: Tribo da Ilha, 2019.

PICULLI, M. Entendendo a iniciação esportiva para o ensino da bocha paralímpica. Dissertação (Mestrado em Educação Física) - Faculdade de Educação Física, Universidade Estadual de Campinas, Campinas, 2016.

QUEIRÓS, P.; LACERDA, T. A importância da entrevista na investigação qualitativa. In: MESQUITA, I.; GRAÇA, A. (org.). Investigação qualitativa em desporto. Porto: Porto, 2013. V. 2. p. 177-206.

SASSAKI, R. K. Inclusão: construindo uma sociedade para todos. 4. ed. Rio de Janeiro: WVA, 2002.

VERGARA, S. C. Métodos de pesquisa em administração. 3. ed. São Paulo: Atlas, 2008.

Recebido: 05.05.2021

Aceito: 19.06 .2021

Revista Extensão \& Cidadania, v. 9, n. 15, p. 64-73, jan./jun. 2021. 